\title{
Gökçeada çevresinde zıpkın ile yakalanan kılıç balıklarının (Xiphias gladius) yaş ve büyüme özellikleri
}

\section{Age and growth rates of swordfish (Xiphias gladius), caught from Gökçeada Island by harpoon fishing}

\author{
Cenk Alver ${ }^{1}$ - Hakan Ayyıldız² • Aytaç Altın² \\ 1 Çanakkale Onsekiz Mart Üniversitesi Fen Bilimleri Enstitüsü Su Ürünleri Anabilim dall, Tezioğlu Yerleşkesi, Çanakkale \\ ${ }^{2}$ Çanakkale Onsekiz Mart Üniversitesi Gökçeada Uygulamalı Bilimler Yüksek Okulu Balıķ̧ılık Teknolojisi Bölümü, Gökçeada Çanakkale \\ *Corresponding author: aytacaltin@gmail.com
}

How to cite this paper:

Alver, C., Ayyıldız, H. \& Altın, A. (2015). Age and growth rates of swordfish (Xiphias gladius), caught from Gökçeada Island by harpoon fishing (in Turkish with English abstract). Ege Journal of Fisheries and Aquatic Sciences, 33(1): 21-26. doi: 10.12714/egejfas.2016.33.1.04

\begin{abstract}
Öz: Bu çalışmada Kuzey Ege Denizinde 24 Mart - 15 Haziran 2015 tarihleri arasında zıpkın ile yakalanan ve Gökçeada'da karaya çıkarılan kılıç balığı, Xiphias gladius bireylerinin yaş ve büyüme özellikleri belirlenmiştir. Alt çene çatal boyları (LJFL) 70 ile $174 \mathrm{~cm}$ ve ağırlıkları 4 - $69 \mathrm{~kg}$ arasında olan toplam 300 adet kılıç balığı analizlerde kullanılmıştır. Boy - ağırlık ilişkisi W $=5 \mathrm{E}-06 \mathrm{~L}^{3,188}\left(\mathrm{R}^{2}=0,948\right)$ olarak hesaplanmıştır. Toplam 83 adet bireyden anal yüzgeç ışınları kullanılarak yaş tayinleri gerçekleştirilmiştir. Yapılan yaş tayinleri sonucunda, kılıç balıklarının 0 - 5 yaş arasında oldukları ve en fazla bireyin 2 yaşında olduğu tespit edilmiştir. Von Bertalanffy büyüme denklemi $L_{\infty}=218,3 ; k=0,193$ ve $t_{0}=-2,1031$ olarak hesaplanmıştır.
\end{abstract}

Anahtar kelimeler: Kılıç balığı, Xiphias gladius, Zıpkın, Kuzey Ege Denizi, Gökçeada

Abstract: In this study, age and growth rates of swordfish Xiphias gladius, caught from north Aegean Sea with landings in Gökçeada Island by harpoon fishing, were determined between 24 March and 15 June 2015. A total of 300 swordfish specimens that ranged between 74 and $174 \mathrm{~cm}$ Lower jaw fork length (LJFL) were used in the analysis. The length-weight relationships were calculated as $W=5 E-06 L^{3.188}\left(R^{2}=0.948\right)$. A total of 83 anal fin rays were used in the analyses. The age-classes ranged from 0 to 5 years, while the samples were dominated by the 2 years old. The von Bertalanffy growth curves were fitted to the length at age data and the estimated parameters of the equation were: $L_{\infty}=218.3 ; k=0.193$ and $t_{0}=-2.1031$.

Keywords: Swordfish, Xiphias gladius, harpoon, North Aegean Sea, Gökçeada

\section{Gíriş}

Kılıç balığı, Xiphias gladius, $0-800 \mathrm{~m}$ derinliklerde (Collette, 1995) Atlantik, Hint ve Pasifik okyanusunda ayrıca Akdeniz, Marmara, Karadeniz ve Azak Denizi'nde dağılım göstermektedir (FAO, 1994). Maksimum boyu $455 \mathrm{~cm}$ olan bu tür, 5 - $27{ }^{\circ} \mathrm{C}$ sıcaklık aralığında yaşamını sürdürmektedir (Nakamura, 1985). Fakat genel olarak termoklin tabakasının üzerinde $18-22{ }^{\circ} \mathrm{C}$ sıcaklık aralığını tercih etmekle beraber, 24 ${ }^{\circ} \mathrm{C}$ 'nin üzerindeki sıcaklıklarda ise üremesi gerçekleşmektedir (Chang vd., 2013). Akdeniz'de üreme döneminin Haziran ayında başlayıp Eylül ayına kadar sürdüğü ve Haziran sonu ile Ağustos ayları arasında maksimum düzeye ulaştığı bildirilmiştir (Nakamura, 1985). Kılıç balıkları seksüel dimorfizm gösterdikleri bilinmektedir. Dişi bireyler erkeklere göre daha hızlı büyümekte ve daha büyük olmaktadır (Tserpes ve Tsimenides, 1995; Sun vd., 2002). Genel olarak bu türün pozitif allometrik büyüme gösterdiği tespit edilmiştir (Alıçlı vd., 2012;
Akyol ve Ceyhan, 2013; Varghese vd., 2013). Bunun yanında dişi bireyler eşeysel olgunluğa erkeklerden daha geç ulaşmakta ve dişi erkek oranı boyuta göre değişmektedir (De Martini vd., 2000; Wang vd., 2007; Varghese vd., 2013). Akdeniz'de ilk üreme boyu $140 \mathrm{~cm}$ olarak rapor edilmiştir (De Metrio $\mathrm{G}$ vd., 1989; Alıçlı vd., 2012). Akdeniz'de yapılan yaş tayini çalışmalarında maksimum 10 yaş tespit edilirken avcılığın yoğun olarak 1-3 yaş arasında gerçekleştiği bildirilmiştir (Tserpes ve Tsimenides, 1995; Valeiras vd., 2008; Alıçlı vd., 2012; Akyol ve Ceyhan, 2013).

Ekonomik açıdan oldukça değerli olan kılıç balığının Türkiye 2005-2014 yılları arasında avcılık verilerine bakıldığında 2005 yılında 425 ton olan av miktarının 2014 yılında 55,7 tona kadar düştüğü görülmektedir (TUIK, 2014). Ege Denizinde ise avcılık 31,8 tona kadar gerilemiştir. Büyük 
akıntı sistemlerinin egemen olduğu ve balıkçıık açısından önemli bir bölge olan Kuzey Ege Denizi, Karadeniz'den gelen nütrient bakımından zengin sular ile birçok balık türü için uygun bir ortam sağlamaktadır (Beşiktepe vd., 1993). Kıııç balıklarının nütrient bakımından zengin olan denizlerde diğer denizlere göre daha fazla avlandıkları bildirilmiş (Young vd., 2006) olmasına rağmen Kuzey Ege Denizi'nde avcılıkta büyük bir azalma görülmüştür. Bu azalma tür üzerindeki yoğun avcllık baskııına işarettir (Akyol ve Ceyhan, 2013). Bu bakımdan türün biyolojik özeliklerinin ve avcıllk miktarlarının takip edilmesi gerekmektedir. Doğru yönetim stratejleri hazırlamak ve uygulamak için öncelikle mevcut kaynakların durumu takip edilmelidir. Bu bakımdan, yapılan bu çalışmanın ana amacı; Kuzey Ege Denizi'nde zıpkınla avlanan kılıç balıklarının yaş ve büyüme özelliklerinin belirlenmesidir.

\section{MATERYAL VE METOT}

Bu çalışma, 24 Mart - 15 Haziran 2015 tarihleri arasında Kuzey Ege Denizi'nde gerçekleştirilmiştir (Şekil 1).

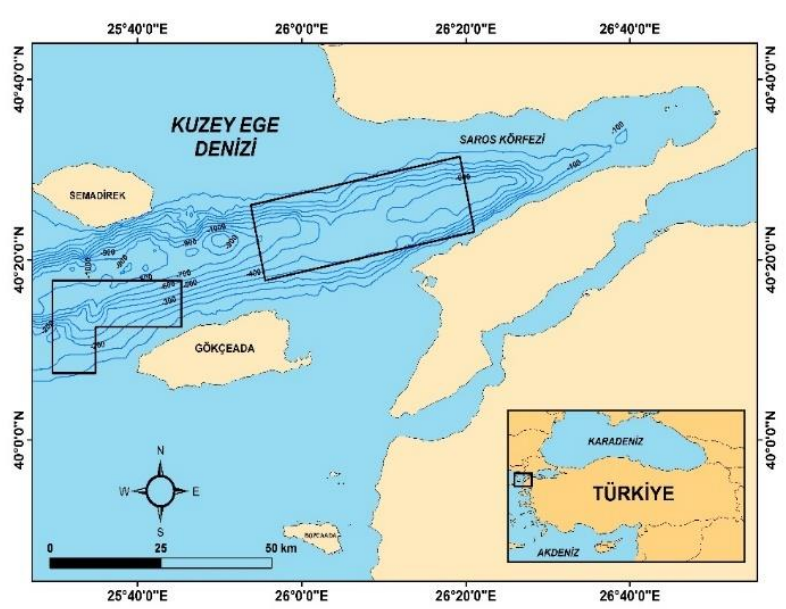

Şekil 1. Gökçeada çevresinde kılıç balığı avcılığı yapılan bölgeler Figure 1. Swordfish harpoon fishing area around Gökçeada

Örneklemeler Çanakkale Onsekiz Mart Üniversitesi Gökçeada Uygulamalı Bilimler Yüksekokuluna ait olan ÇOMÜ 3 isimli ahşap araştırma teknesi (12 m boyunda ve $135 \mathrm{bg}$ beygir gücünde) ile gerçekleştirimiştir. Bunun yanında profesyonel balıkçılar tarafından avlanan ve Gökçeada Kaleköy limanında karaya çıkarılan balıklardan da örnek temin edilmiştir. Tür tayini Whitehead vd. (1986) ile Mater ve Çoker (2004)'e göre yapılmıştır. Örneklerin boyları 200 cm' lik ölçüm tahtaları veya mezura yardımı ile alt çene total boy (LJTL), alt çene çatal boy (LJFL) ve total boy (UJTL) $\mathrm{cm}$ olarak ölçülmüştür (Romeo vd., 2014). Boy-boy ilişkileri doğrusal regresyon analizi kullanılarak hesaplanmıştır. Ağırlık ölçümleri ise balık karaya çıkarıldıktan sonra temizlenmeden tüm ağırlığı (total weight) elektronik tartı yardımı ile alınmıştır.
Boy-ağırlık ilişkisinin belirlenmesinde Ricker (1975)' in W = aLb eşitliğinden faydalanılmıştır. Bu denklemde $\mathrm{W}$, balığın ağırığını (kg); L, alt çene total boy (LJTL) $(\mathrm{cm})$; a ve b büyüme sabitlerini ifade etmektedir. Ayrıca, b değerinin 3' ten farklı olup olmadığı Student's t-test (Zar, 1984) ile test edilmiş̧ir.

Yaş tayini: Kılıç balığının yaş tayinleri birinci anal yüzgecin ikinci diken ışınından yapıımıştır. Her bir anal yüzgeç kaynayan su içerisinde birkaç dakika bekletildikten sonra ikinci ışın deriden ve dokudan uzaklaştırımıştır. Ardından su ile temizlenip ve tamamen kurutulmuştur. Diken ışının kökünün uzunluğunun yarısı kadar üstünden yaklaşık $2 \mathrm{~cm}$ kalınlığında bir kesit alınmış, daha sonra kesit plastik bir kalıp içerisine yerleştirilmiş ve rezin ile doldurularak kalıp hazırlanmıştır. Yaklaşık 12 saat sonra kalıp çıkarılarak 2 veya 3 adet $1 \mathrm{~mm}$ kalınlı̆ında kesit alınmışıı (Şekil 2). Alınan kesitler mikroskop altında incelenerek yaş tayinleri gerçekleştirilmiştir (Tsimendides ve Tserpes, 1989).

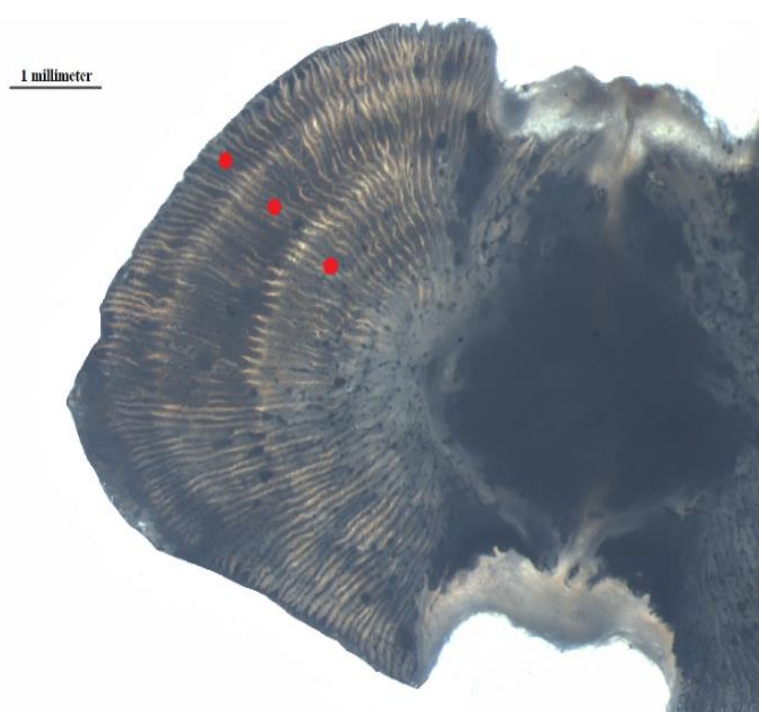

Şekil 2. Kılıç balıklarının birinci anal yüzgecin ikinci sert ışınından alınan kesitin mikroskop altındaki görünüşü ( 3 yaş)

Figure 2. Cross sections of the second ray of the first anal fin of swordfish (age 3)

Boyca büyüme parametrelerinin hesaplanmasında von Bertalanffy (1938) büyüme denklemi kullanılmışıı.

$$
L_{t}=L_{\infty}\left[1-e^{-k(t-10)}\right]
$$

Bu denklemde; $L_{\infty}$ : Balığın teorik olarak ulaşabileceği maksimum boyunu $(\mathrm{cm}), \mathrm{Lt}$ : "t" yaşındaki balığın boyunu $(\mathrm{cm})$, to: balık boyunun teorik olarak sıfır olduğu yaş (yıl) ve k: büyüme katsayısını (yıl-1) göstermektedir. 


\section{BULGULAR}

Gökçeada çevresinde tarafımızdan örneklenen boyları 83 - $162 \mathrm{~cm}$ (LJFL) ve ağırlıkları 5,11 - 60,6 kg arasında değişen toplam 10 adet kılıç balığı örneklenmiştir. Profesyonel balıkçılar tarafından ise boyları 70 - $174 \mathrm{~cm}$ (LJFL), ağırlıkları 4 - $69 \mathrm{~kg}$ arasında değişen 290 adet kılıç balığı yakalanmış ve bu bireylerin tamamının boy ağırlık ölçümleri yapılmıştır (Şekil 3).

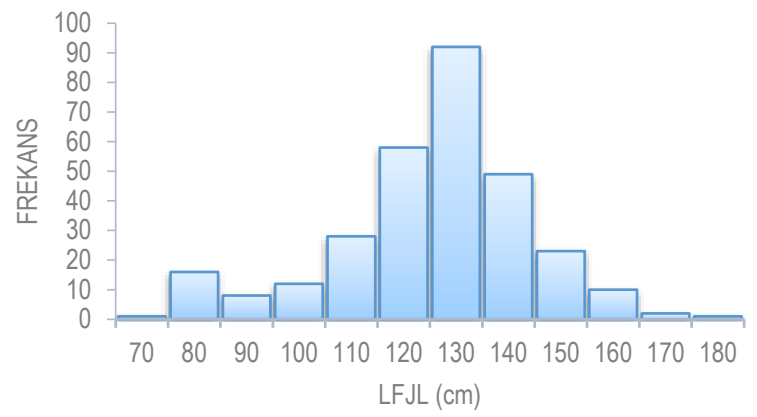

Şekil 3. Gökçeada çevresinde zıpkınla yakalanan kılıç balıklarının boy $(\mathrm{cm})$ frekans grafiği $\mathrm{N}=300$

Figure 3. Length-frequency distributions of the swordfish captured by harpoon fishing from Gokçeada $\mathrm{N}=300$

\section{Boy-ağırlık ve boy-boy ilişsileri}

Örneklenen kılıç balıklarının bireysel boy (LJTL) ve ağırlıklarından hesaplanan boy-ağılık iliskisi; $W=5 E-06$ L3,188 olarak bulunmuştur (Şekil 4).

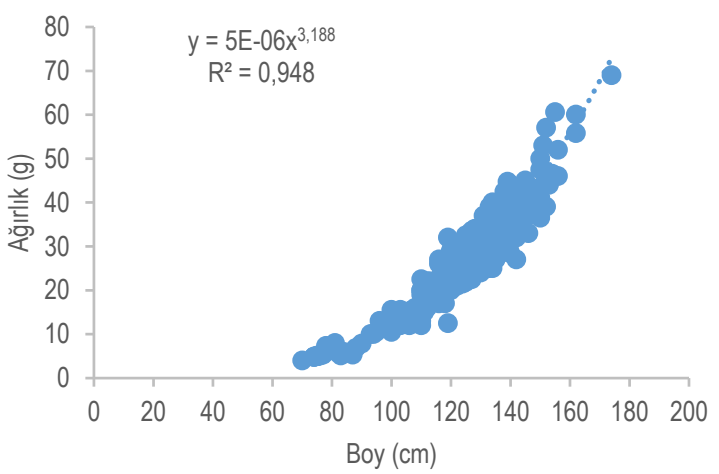

Şekil 4. Gökçeada çevresinde zıpkınla yakalanan kılıç balıklarının boy (LJFL) -ağırlık ilişkisi $\mathrm{N}=300$

Figure 4. Length-weight relationships of the swordfish captured by harpoon fishing from Gokçeada $\mathrm{N}=300$

İstatistiksel olarak "b" değerinin 3'ten önemli derecede farkl olduğu tespit edilmiştir $(P<0,01)$. Kılıç balıklarının boy-boy ilişkileri UJTL-LJTL, UJTL-LJFL ve LJTL-LJFL Tablo 1'de verilmiştir. Boy ölçümlerinin birbirleri ile aralarında kuvvetli doğrusal bir ilişki olduğu tespit edilmiştir.
Tablo 1. Gökçeada çevresinde zıpkınla yakalanan kılıç balıklarının boy-boy ilişkisi parametreleri

Table 1. Length-length relationships parameters of the swordfish captured by harpoon fishing from Gokçeada

\begin{tabular}{llllll}
\hline Boy-boy ilişkileri & $\mathbf{N}$ & $\mathbf{a}$ & $\mathbf{b}$ & $\mathbf{R}^{\mathbf{2}}$ & $\mathbf{P}$ \\
\hline UJTL-LJTL & 300 & 7,215 & 0,670 & 0,94 & $<0,01$ \\
UJTL-LJFL & 300 & 13,480 & 0,561 & 0,95 & $<0,01$ \\
LJTL-LJFL & 300 & 10,490 & 0,815 & 0,96 & $<0,01$ \\
\hline
\end{tabular}

\section{Yaş ve büyüme özellikleri}

Tarafımızdan yakalanan örneklerin tamamından (10 adet) ve profesyonel balıkçılardan elde edilen örneklerin 73 adetinden anal yüzgeç ışını alınmıştır. Diğer balıkların anal yüzgeç ışınlarının alınmasına; balığın piyasa değerinin düşeceği endişesinden dolayı balıkçılar tarafından izin verilmemiştir. Böylelikle toplam 83 adet bireyden yaş tayinleri gerçekleştirilmiştir.

Yapılan yaş tayinleri sonucunda kılıç balığı örneklerinin 0-5 yaş grupları arasında dağılım gösterdikleri ve en fazla bireyin 2 yaş grubunda olduğu $(n=33)$ tespit edilmiştir (Tablo 2).

Tablo 2. Gökçeada çevresinde zıpkınla yakalanan kılıç balıklarının boy (LJFL) yaş anahtarı $\mathrm{N}=83$

Table 2. Age-length key of the swordfish captured by harpooning from Gokçeada Island N = 83

\begin{tabular}{|c|c|c|c|c|c|c|c|}
\hline \multirow{2}{*}{$\begin{array}{l}\text { Boy grupları } \\
\text { (LJFL) }\end{array}$} & \multicolumn{6}{|c|}{ Yaş Grupları } & \multirow{2}{*}{ Genel Toplam } \\
\hline & 0 & 1 & 2 & 3 & 4 & 5 & \\
\hline $70-79$ & 5 & 5 & & & & & 10 \\
\hline $80-89$ & & 3 & & & & & 3 \\
\hline $90-99$ & & 3 & & & & & 3 \\
\hline $100-109$ & & 5 & 1 & & & & 6 \\
\hline $110-119$ & & 4 & 9 & & & & 13 \\
\hline $120-129$ & & & 17 & 1 & & & 18 \\
\hline $130-139$ & & & 6 & 7 & & & 13 \\
\hline $140-149$ & & & & 5 & 3 & & 8 \\
\hline $150-159$ & & & & & 5 & 1 & 6 \\
\hline $160-169$ & & & & & & 2 & 2 \\
\hline $170-179$ & & & & & & 1 & 1 \\
\hline Genel Toplam & 5 & 20 & 33 & 13 & 8 & 4 & 83 \\
\hline
\end{tabular}

von Bertalanffy büyüme denklemi parametreleri ise $L_{\infty}=218,3$; $\mathrm{k}=0,193$ ve $\mathrm{t}_{0}=-2,1031$ olarak bulunmuştur (Şekil 5).

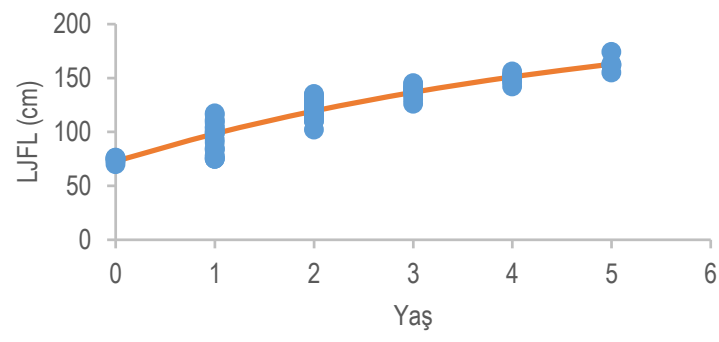

Şekil 5. Gökçeada çevresinde zıpkınla yakalanan kılıç balıklarının von Bertalanffy büyüme grafiği

Figure 5. von Bertalanffy growth curves of the swordfish captured by harpoon fishing from Gokceada 


\section{TARTIŞMA}

Kılıç balığının Akdeniz'deki avcılığı ICCAT (The International Commission for the Conservation of Atlantic Tunas) kontrolü altında olup, minimum yakalama boyu (LJFL) $90 \mathrm{~cm}$ veya $10 \mathrm{~kg}$ olarak olarak önerilmektedir (ICCAT, 2013). Ülkemizde "3/1 Numaralı Ticari Amaçı Su Ürünleri Avcılığını Düzenleyen Tebliğ (Tebliğ No: 2015/65)" de bu yasal sınırlama $125 \mathrm{~cm}$ (çatal boy) olarak belirtilmiştir. Bu bakımdan kılıç balığı boy özelliklerinin bilinmesi avcılığın kontrolü açısından önem arz etmektedir. Bilindiği üzere alt çene çatal boy (LJFL) ölçümü kılıç balığı boy değerlendirmelerinde esas alınmaktadır. Romeo vd. (2014) yapmış oldukları çalışmada kılıç balığı toplam boyu (UJFL) ile alt çene çatal boy (LJFL) arasında \%99 ilişki olduğunu bildirmişlerdir. Benzer bir şekilde yapılan bu çalışmada kılıç balığı alt çene total boy (LJTL), alt çene çatal boy (LJFL) ve total boy (UJTL) aralarında kuvvetli doğrusal bir ilişki olduğu tespit edilmiştir. Bu bakımdan kılıç balığı boy değerlendirmelerin tüm boy ölçümlerinden yapılabileceği düşünülmektedir.

Akyol ve Ceyhan (2011) Ege Denizi kılıç balığı avcılığının 51 ile $242 \mathrm{~cm}$ (LJFL) arasında değiştiğini ve gırgır, galsama ağları (yüzer ağlar) ve paragat ile yapılan avcılığın 70-80 cm boy aralığında yoğunlaştığını rapor etmişlerdir. Bilindiği üzere bu boy aralığı türün ilk üreme boyu altındadır (De Metrio vd. 1989). Aynı çalışmada türün üzerinde yoğun bir av baskısı olduğu da bildirilmiştir. 2015 yılında Gökçeada çevresinde zıpkın ile yakalanan kılıç balıklarının boy aralığının 70-174 cm arasında olduğu (LJFL) ve özellikle 120 ile $140 \mathrm{~cm}$ (LJFL) arasında yoğunlaştığı belirlenmiştir. Toplam karaya çıkarılan balığın yaklaşık \% 30' u yasal boy sınırlamasının altındadır. Bu durumunda türün populasyonunu etkilediği düşünülmektedir. Bilindiği üzere zıpkın ile avcılık görme esasına dayandığından bu avcılık yönteminin seçiciliği yüksektir. Diğer bir taraftan avcılığın kontrolü açısından türün boy ağırlık ilişkisinin de bilinmesi önemlidir. Çalışmamamızda türün boy ağırlık ilişkisi hesaplanmış ve a ve b değerleri tespit edilmiştir. Ayrıca boyağırlık ilişkisi denklemi türün pozitif allometrik büyüme modeline sahip olduğunu göstermektedir. Boy-ağırlık ilişkisi parametreleri sıcaklık, besin miktarı, üreme koşulları ve içindeki bulundukları habitat karakteristikleri gibi ekolojik faktörlerden etkilenebilmektedir (Wootton, 1992). Kılıç balıkları oldukça geniş bir yayılım alanına sahip olmalarına rağmen, boy ağırlık ilişkisi üzerine farklı bölgelerde yapılan çalışmalarda benzer sonuçlar elde edilmiştir (Wang vd., 2007; Cerna, 2009; Akyol ve Ceyhan, 2011; Alıçlı vd., 2012; Akyol ve Ceyhan, 2013; Varghese vd., 2013).

Kuzey Ege Denizi büyük akıntı sistemlerinin etkisindedir. Özellikle boğazlar sisteminden gelen nütrient bakımından zengin Karadeniz suları bölgeyi zengin kılmaktadır (Beşiktepe vd., 1993). Bu bakımdan kılıç balığının büyüme özelliklerinde değişiklik olması beklenebilir. von Bertalanffy büyüme parametrelerinden $\mathrm{K}$ değeri balığın $\mathrm{L}_{\infty}$ değerine ne kadar hızlı ulaştığını göstermektedir. Bazı türler $L_{\infty}$ değerine hızla ulaşırlar ve yüksek $\mathrm{K}$ değerine sahiptirler. Bazı türler ise $L_{\infty}$ değerine uzun zaman sonra ulaşırlar ve düşük $\mathrm{K}$ değerine sahiptirler (Sparre ve Veneme, 1998). Genel olarak brody büyüme katsayısı (K) bir türün genetik bir özelliği olarak nitelendirilmektedir (Čikeš Keč ve Zorica, 2013). Yapılan bu çalışmada, kılıç balığının brody büyüme katsayısı düşük bir değere sahip olduğu $(0,19)$ tespit edilmiştir ve diğer çalışmalarla benzerlik göstermektedir. to değeri, balığın yumurtadan çıkmadan önceki kuramsal yaşını ifade etmektedir. Yapılan bu çalışmada elde edilen to değeri, Şili (Cerna, 2009), Batı Akdeniz (Valeiras vd., 2008), Doğu Akdeniz (Alıçlı vd., 2012) ve Ege Denizi'nden (Akyol ve Ceyhan, 2013) elde edilen sonuçlarla büyük benzerlik göstermektedir. Diğer bir parametre olan $L_{\infty}$ değeri türün kuramsal olarak ulaşabileceği maksimum boy değerini ifade etmektedir ve bu çalışmada $218,3 \mathrm{~cm}$ olarak tespit edilmiştir (Tablo 3).

Tablo 3. Farklı bölgelerinden elde edilen kılıç balığı von Bertalanffy büyüme denklemi parametreleri

Table 3. Parameters of the von Bertalanffy growth curves of swordfish from different regions

\begin{tabular}{lllllll}
\hline Bölge & Yaş & Cinsiyet & L $_{\infty}$ & $\mathbf{k}$ & $\mathbf{t}_{0}$ & Referans \\
\hline Ege Denizi & $0-7$ & $\mathrm{D}$ & 220 & 0,25 & $-1,52$ & Tsimenides ve Tserpes 1989 \\
Ege Denizi & $0-6$ & $\mathrm{E}$ & 194 & 0,34 & $-1,22$ & Tsimenides ve Tserpes 1989 \\
Ege Denizi & $0-4$ & $\mathrm{D}+\mathrm{E}$ & 283,6 & 0,15 & $-2,09$ & Akyol ve Ceyhan, 2013 \\
Doğu Akdeniz & $1-7$ & $\mathrm{D}+\mathrm{E}$ & 252,0 & 0,13 & $-2,43$ & Alıclı vd. 2012 \\
Doğu Akdeniz & $0-9$ & $\mathrm{D}+\mathrm{E}$ & 238,6 & 0,19 & $-1,40$ & Tserpes ve Tsimenides 1995 \\
Batı Akdeniz & $0-10$ & $\mathrm{D}$ & 263,5 & 0,12 & $-2,27$ & Valeiras vd. 2008 \\
Batı Akdeniz & $0-10$ & $\mathrm{E}$ & 185,5 & 0,22 & $-1,97$ & Valeiras vd. 2009 \\
Avustralya & $0-2$ & $\mathrm{D}+\mathrm{E}$ & 323,2 & $-0,08$ & 4,00 & Young vd. 2003 \\
Avustralya & $0-2$ & $\mathrm{D}+\mathrm{E}$ & 249,2 & $-0,13$ & 3,30 & Young vd. 2003 \\
Tayvan & $0-12$ & $\mathrm{D}$ & 300,7 & 0,04 & $-0,75$ & Sun vd. 2002 \\
Tayvan & $0-12$ & $\mathrm{E}$ & 213,1 & 0,09 & $-0,63$ & Sun vd. 2002 \\
Şili & $1-13$ & $\mathrm{D}$ & 321,0 & 0,13 & $-2,46$ & Cerna, 2009 \\
Şili & $1-13$ & $\mathrm{E}$ & 279,0 & 0,16 & $-2,65$ & Cerna, 2009 \\
\hline Kuzey Ege Denizi & $\mathbf{0 - 5}$ & $\mathrm{D}+\mathrm{E}$ & $\mathbf{2 1 8 , 3}$ & $\mathbf{0 , 1 9}$ & $\mathbf{- 2 , 1 0}$ & Bu çalışma \\
\hline
\end{tabular}


Farklı bölgelerde yapılan çalışmalarda bu türün $L_{\infty}$ değerinin genel olarak bizim çalışmamızla benzer sonuçlar verdikleri ve bulunan en yüksek değerin ise $323,2 \mathrm{~cm}$ olduğu belirlenmiştir (Young vd., 2003).

Sonuç olarak Kuzey Ege Denizinde yapılan zıpkın ile kılıç balığı avcılığının yaklaşık \%70' inin yasal boy aralığında yapıldığı ve oseanodrom bir tür olan kılıç balığının büyüme parametrelerinin diğer bölgelere nazaran büyük değişiklikler göstermediği tespit edilmiştir. Bilindiği üzere insan kaynaklı etkiler türlerin biyolojik özelliklerini değiştirmektedir. Özellikle üzerinde yoğun av baskısı olan balık türlerinin ilk üreme boyu ve maksimum boyunda değişiklikler olmaktadır. Bu bakımdan insan kaynaklı etkilerin ekosistem üzerindeki etkisi görebilmek amacı ile balık türlerinin biyolojik özelliklerinin takip edilmesi gerekmektedir. Predatör türlerin varlığı o ekosistemin sağlıklı işlediğinin göstergesidir. Bu bakımdan kılıç balığı gibi ekonomik ve ekolojik açıdan önemli türlerin biyolojilerinin takip edilmesi gerekmektedir

\section{TEŞEKKÜR}

Bu çalışma ÇOMÜ BAP 2015-420 nolu proje tarafından desteklenmiştir. Ayrıca bu çalışma bir yüksek lisans tezi kapsamında gerçekleştirilmiştir. Çalışmanın örnekleme aşamasında çok büyük emekleri olan ÇOMÜ 3 teknesi kaptanı Yılmaz Tokoğlu'na ve Yüksek Lisans Öğrencisi Mustafa Emanet'e ayrıca harita çiziminde yardımcı olan Arş. Gör. Semih Kale'ye teşekkür ederiz.

\section{KAYNAKÇA}

Abid, N. \& Idrissi, M. H. (2009). Analysis of the size data of swordfish (Xiphias gladius) caught by the Moroccan driftnet fishery operating in the Mediterranean Sea. Collective Volume of Scientific Papers, ICCAT, 64(6), 2093-2104

Akyol, O. \& Ceyhan, T. (2011). The Turkish Swordfish Fishery. Collective Volume of Scientific Papers. ICCAT, 66(4), 1471-1479.

Akyol, O. \& Ceyhan, T. (2013). Age and growth of swordfish (Xiphias gladius L.) in the Aegean Sea. Turkish Journal of Zoology, 37(1): 59-64.

Alıçı, T. Z., Oray, I. K., Karakulak, F. S. \& Kahraman, A. E. (2012). Age, sex ratio, length-weight relationships and reproductive biology of Mediterranean swordfish, Xiphias gladius L., 1758, in the eastern Mediterranean. African Journal of Biotechnology, 11(15): 3673-3680.

Beşiktepe, Ş., Özsoy, E. \& Ünlüata, Ü. (1993). Filling of the Marmara Sea by the Dardanelles Lower Layer Inflow. Deep Sea Researh, 40: 1815-1838. doi: 10.1016/0967-0637(93)90034-Z

Cerna, J. F. (2009). Age and growth of the swordfish (Xiphias gladius Linnaeus 1758) in the southeastern Pacific off Chile (2001). Latin American Journal of Aquatic Research, 37(1): 59-69. doi: 10.3856/vol37-issue1-fulltext-5

Chang, Y. J., Sun, C. L., Chen, Y., Yeh, S. Z., DiNardo, G. \& Su, N. J. (2013) Modelling the impacts of environmental variation on the habitat suitability of swordfish, Xiphias gladius, in the equatorial Atlantic Ocean. Ices Journal of Marine Science, 70(5): 1000-1012. doi: 10.1093/icesjms/fss 190

Čikeš Keč, V. \& Zorica, B. (2013). Length-weight relationship, age, growth and mortality of Atlantic chub mackerel Scomber colias in the Adriatic Sea. Journal of the Marine Biological Association of the United Kingdom, 93(2): 341-349. doi: $10.1017 /$ S0025315412000161

Collette, B. B. (1995). Xiphiidae. Peces espada, In W. Fischer, F. K., W. Schneider, C. Sommer, K.E. Carpenter and V. Niem (eds), Guia FAO para Identification de Especies para lo Fines de la Pesca (pp.1651-1652) Pacifico Centro-Oriental, Rome: FAO..

De Martini, E. E., Uchiyama, J. H. \& Williams, H. A. (2000). Sexual maturity, sex ratio, and size composition of swordfish, Xiphias gladius, caught by the Hawaii-based pelagic longline fishery. Fishery Bulletin, 98(3): 489-506.

De Metrio G., Megalofonou P. \& Tselas S. N. T. (1989). Fishery and Biology of the Swordfish Xiphias gladius L., 1758 in Greek waters. FAO Fisheries Report, 412: 135-145.

FAO, F. D. (1994). World review of highly migratory species and straddling stocks. (70p), Rome

ICCAT. (2013). Management Measures for Mediterranean Swordfish in the Framework of ICCAT [Rec. 11-03]
Macias, D., Hattour, A., De la Serna, JM. \& Gómez-Vives MJ.D.G. (2005) Reproductive characteristic of swordfish (Xiphias gladius) caught in the Southwestern Mediterranean during 2003. Collective Volume of Scientific Papers ICCAT, 58(2): 454-459.

Mater, S. \& Çoker, T. (2004). Ichthyoplankton atlas of Turkish Seas, Bornova, Izmir: Ege Universty press, $210 \mathrm{p}$.

Nakamura, I. (1985). FAO species catalogue. Vol. 5. Billfishes of the World. An annotated and illustrated catalogue of marlins, sailfishes, spearfishes and swordfishes known to date. FAO Fish. Synop., 125(5).

Ricker, W. E. (1975). Computation and interpretation of biological statistics of fish populations. Bulletin of the Fisheries Research Board of Canada, 382 pp.

Romeo, T., Consoli, P., Battaglia, P. \& Andaloro, F. (2014). A support to manage the swordfish (Xiphias gladius Linnaeus, 1758) IUUF (illegal, unreported and unregulated fishing): an easy method to identify the legal size. Journal of Applied Ichthyology, 30(1): 114-116. doi: 10.1111/jai.12306

Sparre, P. \& Veneme, S. C. (1998). Introduction to tropical fish stock assessment. Part 1. Manual. FAO Fisheries Technical Paper No, 306(1), 1.

Sun, C. L., Wang, S. P. \& Yeh, S. Z. (2002). Age and growth of the swordfish (Xiphias gladius L.) in the waters around Taiwan determined from anal-fin rays. Fishery Bulletin, 100(4): 822-835.

Tserpes, G. \& Tsimenides, N. (1995). Determination of age and growth of swordfish, Xiphias-gladius I, 1758, in the eastern Mediterranean using anal-fin spines. Fishery Bulletin, 93(3): 594-602.

Tsimendides, N. \& Tserpes, G. (1989). Age-Determination and growth of swordfish Xiphias-gladius L, 1758 in the Aegean Sea. Fisheries Research, 8(2): 159-168. doi: 10.1016/0165-7836(89)90029-5

TUiK (2014). Turkstat, Fishery statistics. http://www.tuik.gov.tr/. Access date: 09.12 .2015

Valeiras, X., de la Serna, J. M., Macias, D., Ruiz, M., Garcia-Barcelona, S., Gomez, M. J. \& Ortiz de Urbina, J. M. (2008). Age and growth of swordfish (Xiphias gladius) in the Western Mediterranean Sea. Collective Volume of Scientific Papers, ICCAT, 62(44): 1112-1121.

Varghese, S. P., Vijayakumaran, K., Anrose, A. \& Mhatre, V. D. (2013). Biological Aspects of Swordfish, Xiphias gladius Linnaeus, 1758, Caught During Tuna Longline Survey in the Indian Seas. Turkish Journal of Fisheries and Aquatic Sciences, 13(3): 529-540.

von Bertalanffy, L. (1938). A quantitative theory of organic growth (inquiries on growth laws II). Human Biology, 10: 181-213. 
Wang, S. P., Sun, C. L., Punt, A. E. \& Yeh, S. Z. (2007). Application of the sex specific age-structured assessment method for swordfish, Xiphias gladius, in the North Pacific Ocean. Fisheries Research, 84(3): 282-300. doi: 10.1016/j.fishres.2006.11.027

Whitehead, P., Bauchot, M., Hureau, J., Nielsen, J. \& Tortonese, E. (1986) Fishes of the north-eastern Atlantic and the Mediterranean (1473 p) Volume I, II and III, Paris: UNESCO, Paris.

Wootton, R. J. (1992). Constraints in the evolution of fish life histories. Netherlands Journal of Zoology, 42: 291-303.
Young, J., Drake, A. \& Groisson, A.L. (2003). Age and Growth of Broadbill Swordfish (Xiphias gladius) from Eastern Australian Waters - preliminary results. CSIRO, Division of Marine Research Hob art, Tasmania Australia.

Young, J., Lansdell, M., Riddoch, S. \& Revill, A. (2006). Feeding ecology of broadbill swordfish, Xiphias gladius, off eastern Australia in relation to physical and environmental variables. Bulletin of Marine Science, 79(3): 793-809.

Zar, J. H. (1984). Biostatistical Analysis (620 p). Prentice-Hall, Englewood Cliffs, NJ, USA. 